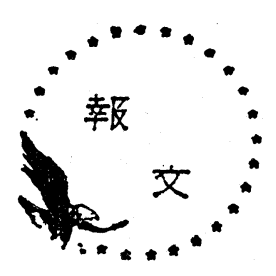

\title{
拡散燃焼における $\mathrm{NO}_{x}$ の生成に \\ 関する研究 (II)
}

一抑制対策のモデル化実験と $\mathrm{NO} x$

生成過程の推算法

一昭 和 48 年 9 月 7 日 受 理一

早稲田大学理工学部 永田勝也 - 望月正彦*

\section{1. まえがき}

$\mathrm{NO}_{x}$ 生成機構については, 1946年の Zeldovich 以 来 ${ }^{1)}$, 数多くの人々によって研究がなされ, 現在では, 特に低空気比 $(<1.0)$ で著しい火炎面での急激な NO の生成 ${ }^{2) 3)}$ (Prompt NO) のメカニズムに対する問題 以外は，一応結論が得られているといってもよかろ 5。火炎後流の NO 生成に対しては, 次に示すよう な拡大 Zeldovich 機構で十分説明ができるとされてい る。

$$
\begin{aligned}
& \mathrm{N}_{2}+\mathrm{O} \rightleftarrows \mathrm{NO}+\mathrm{N} \\
& \mathrm{O}_{2}+\mathrm{N} \rightleftarrows \mathrm{NO}+\mathrm{O} \\
& \mathrm{N}+\mathrm{OH} \rightleftarrows \mathrm{NO}+\mathrm{H}
\end{aligned}
$$

以上の上らな $\mathrm{NO}_{x}$ 生成機構に関する研究は, フラ ット・フレーム・バーナーやショックチューブを用いた 非常に単純な, 基礎的なもので, 実際の燃焼装置でお こっている状況とは大きなへだたりがある。工業的な 規模の装置でとられる燃焼形態は拡散燃焼であり, 燃 焼室内でのフローパターン，燃料と突気の混合特性な ぞによって燃焼の状況, $\mathrm{NO}_{x}$ の生成量が大幅にかわ ってくる。このような害際の装置における $\mathrm{NO}_{x}$ の生 成を推定する場合には, 燃焼状況の複雑さが故に前述 のZeldovich 以後研究されてきた化学反応機構はほと んど役立たないといってよい。筆者らは兼々， $\mathrm{NO}_{x}$ 生成における基礎研究と実装置への応用の結合をらむ 研究の不足を痛感してきた。そこでここでは, 燃焼用 空気に窒素 $\left(\mathrm{N}_{2}\right)$, 二酸化炭素 $\left(\mathrm{CO}_{2}\right)$, アルゴン (A) などを混入して排ガス循環のモデル化した実験を行な らとともに, それらのデータを用いて, 筆者らの独得 の方法により実装置に近い燃焼形式をもつ実験装置に おける $\mathrm{NO}_{x}$ 生成量の推定法を示している。またその 他, 二段燃焼の効果についても調べた。

\footnotetext{
* 現 千代田化工建設株式会社
}

\section{2. 実験装置および方法}

使用した実験装置は第 1 報に述べたものと同一であ る。排ガス循環および二段燃燒のモデル化実験の方法 も第 1 報に記述されているので参照して頂きたい。

測定法も同様であるが，ただし，ここでは燃焼室両 側面の 10 対の測定孔において, $\mathrm{NO}_{x}$ 濃度, 燃焼ガス 組成の他に燃焼ガス温度の計測も行なっている。燃焼 ガス温度は Pt-PtRh 13\% 熱電対により測定し, 結果 には放射の影響を補正して表示している。

\section{3. 抑制対策のモデル化実験}

\section{$3 \cdot 1$ 排ガス循環}

Fig. 1 は, 排ガス循環を行なら代りに, 燃焼用空気 中にその成分である $\mathrm{N}_{2}$ や $\mathrm{CO}_{2}$ あるいは $\mathrm{A}$ などの 希勫物を混入して, $\mathrm{NO}_{x}$ 生成に対する影響を調べた ものである。予混合率は, この場合, 第 1 報でも述心゙ たように燃焼用空気流量 $Q_{a 1}$ に対する希釈ガス流量

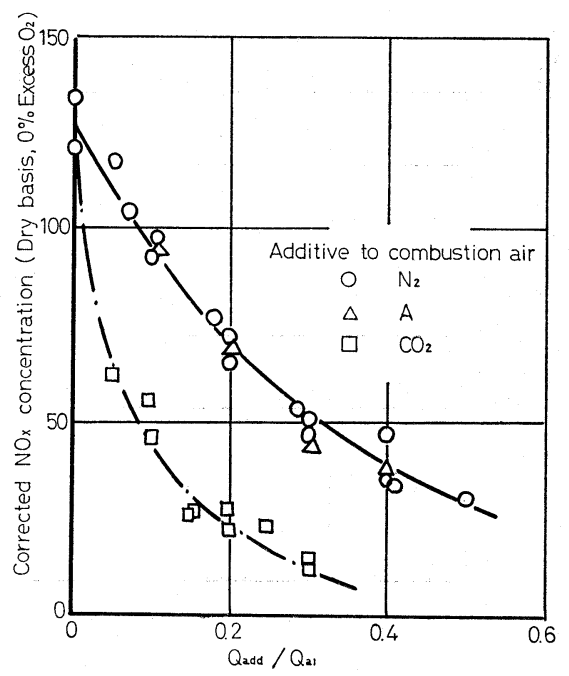

Fig. $1 \mathrm{NO}_{x}$ reduction through the pre-mixing of additives to the combustion air 
$Q_{a d d}$ で定義する。

$$
Q_{a d d} / Q_{a 1}
$$

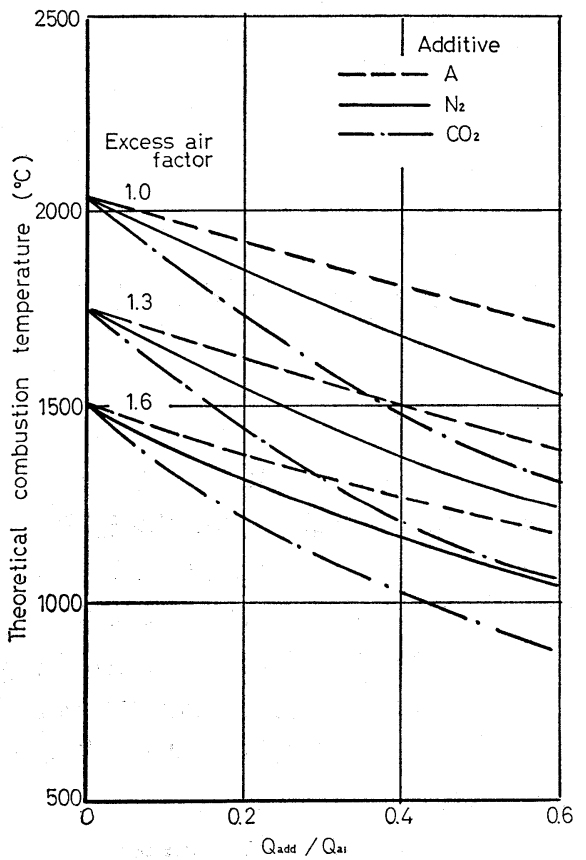

Fig. 2 Relation between $Q_{a d d} / Q_{a 1}$ and theoretical combustion temperature

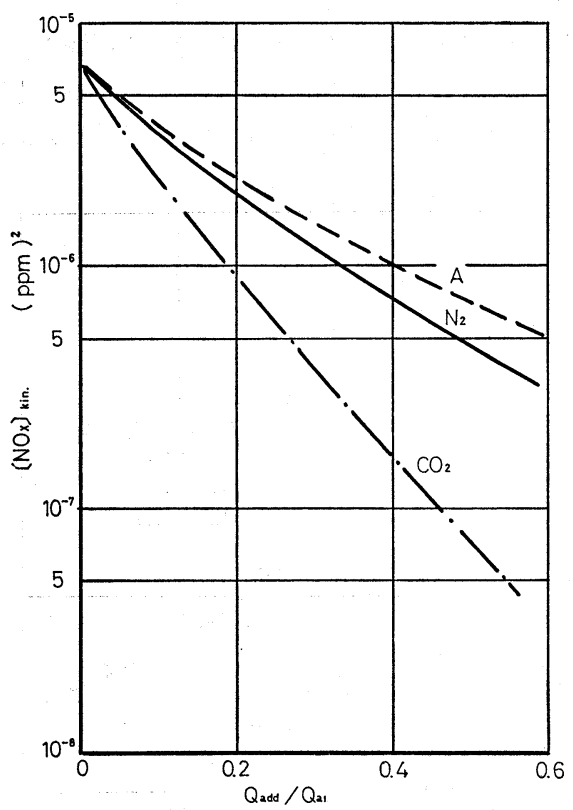

Fig. 3 Kinetic consideration about theeffect of the pre-mixing of additives to the combustion air
図からわかるように, $Q_{a d d} / Q_{a 1}$ が増加すると，か なり $\mathrm{NO}_{x}$ 生成量が低下寸る。希釈物の種類について は $\mathrm{N}_{2}, \mathrm{~A}$ に比べて $\mathrm{CO}_{2}$ の効果が非常に大きい。

Fig. 2 は各種希瀵物の混入率に対する理論燃燒温度 の変化を示したものである。この図のように $\mathrm{CO}_{2}$ は 熱容量が大きいため, 同一予混合率の場合には $\mathrm{N}_{2}, \mathrm{~A}$ より燃焼温度が低い。そこで $\mathrm{NO}_{x}$ 量も少なくなるも のと考えられる。

$\mathrm{N}_{2}$ も $\mathrm{A}$ と比較するとかなり理論燃燒温度が低く， その関係からいけば $\mathrm{NO}_{x}$ 量も低くなるはずである が，実測では Fig. 1 に示されるようにほぼ同程度の 排出量を示す。これは $\mathrm{N}_{2}$ 予混合の場合には，燃焼域 での $\mathrm{N}_{2}$ 分圧が上昇するためであり, 反応温度を理論 燃燒温度として，滞留時間一定の場合の第 1 報の(7)式 により速度論的な $\mathrm{NO}_{x}$ 生成量を求めてみると, Fig. 3 に示すように $\mathrm{A}$ と $\mathrm{N}_{2}$ では $\mathrm{NO}_{x}$ 量が非常に近い 值を示す。

\section{$3 \cdot 2$ 二段燃焼}

二段燃焼の効果を示したのが Fig. 4 である。この 場合，一段目と二段目の空気を合せた総合空気比 $\lambda_{T}$ は 1.2 一定にし，両者の配分を変えて実験を行なって いる。図には一段目空気比 $\lambda_{1}$ に対する $\mathrm{NO}_{x}$ 量の関 係を示している。また，燃料中に空気を予混合し，二 段燃焼を行なう場合の混合特性の影響についても調べ ている。

一段目の燃焼域における混合が悪い状態で二段燃焼 を行ならと， $\lambda_{1}$ が低い場合 $(<0.8)$ を除き, 同じ総 合空気比で普通燃焼（二段燃焼を行なわせない，これ

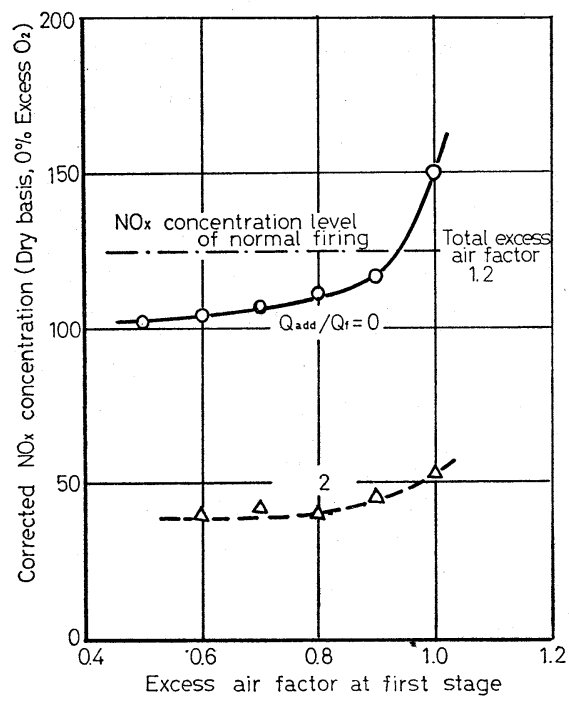

Fig. 4 Effect of two-stage combustion 
まで述べてきたような燃焼方式を，二段燃焼と対比す るときにはこのように呼ぶことにする）を行なった場 合より $\mathrm{NO}_{x}$ 量は高くなる。これは， $\lambda_{1}$ が高い状態 では, 二段燃焼を行なっても混合が悪いため, 一段目 の燃焼域の空気比は設定值通りの值は示さず，かなり 高い, 1.0 に近い值をもつことによるものと考えられ る。この場合，1段目においてもかなりの $\mathrm{NO}_{x}$ が生 成し, さらに 2 段目の燃燒域も含めて高温の領域が長 くなるので全体的な $\mathrm{NO}_{x}$ の生成量は普通燃燒の場合 を上まわってしまう。しかし，混合が不良な場合にも $\lambda_{1}$ が非常に小さいと, 燃焼域での $\mathrm{O}_{2}$ 分圧む低下し, また燃燒温度も下るため， 2 段然焼の効果が若干表わ れてくる。

一方, 混合が良好な場合には, 一段目でかなり急速 な燃焼がおこり, 燃焼域における $\mathrm{O}_{2}$ 分圧とともに燃 焼温度も低下するため $\mathrm{NO}_{x}$ 量はかなり低い值を示 す。またこの場合, 燃焼の完了が速いので, 高温域で の燃焼ガスの滞留時間の減少も $\mathrm{NO}_{x}$ 生成抑制に寄与 している。

このように二段然焼によって $\mathrm{NO}_{x}$ の抑制をはかる 場合には, 一段目における燃料と空気の混合特性をで きるだけ良好にしたほうがその効果が大きい。特に,

一般の重油だきボイラーでは，一段目の空気比が 1.0 以下の燃焼を行なわせなければならない二段燃焼を採 用すると, 未然分の発生が心配されるわけであるが, その防止の上からいっても一段目での混合の良好化は 望まれることである。

\section{4. 拡散燃焼装置における $\mathrm{NO}_{x}$ 生成量の推 算法}

$4 \cdot 1 \quad \mathrm{NO}_{x}$ 生成速度の推定

次にこれまで述べたデータを用い, 筆者らの独自の 方法によって求めた拡散燃焼における $\mathrm{NO}_{x}$ 生成速度 について若干の考察を行なってみる。ここで利用する のは燃焼用空気の予熱の影響 (第 1 報) と燃焼用空気 に $\mathrm{N}_{2}, \mathrm{CO}_{2}, \mathrm{~A}$ を予混合したときの結果である。こ れらを選んだのは, 燃焼温度の変化が大きく $\mathrm{NO}_{x}$ 生 成に対する温度依存性を広範囲にわたって把握できる からである。

理論燃焼温度の逆数と上記実験条件における換算濃 度を $\mathrm{N}_{2}$ と $\mathrm{O}_{2}$ の平衡濃度の積で除したものとの関係 を示したのが Fig. 5 である。この場合, 次のような 仮定をおくと，NO（第1報でも述べたように理論的 な取扱いにおいては $\mathrm{NO}_{x}$ を $\mathrm{NO}$ と考えてよい）の 生成反応を見かけ上,

$$
\mathrm{N}_{2}+\mathrm{O}_{2} \stackrel{k}{\longrightarrow} 2 \mathrm{NO}
$$

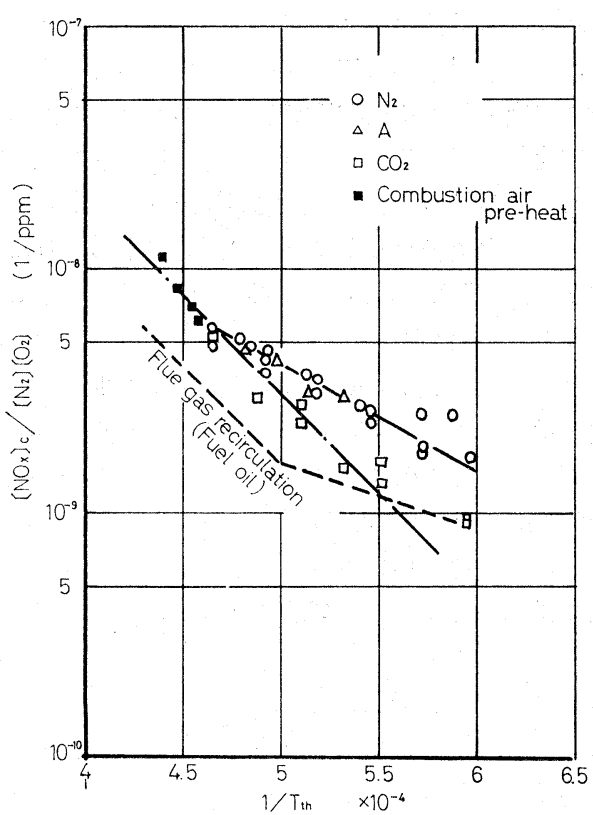

Fig. 5 Determination of apparant activation energy

$$
k=f \cdot \exp .(-E / R T)
$$

とした場合の活性化エネルギーの值が求められる。 仮定

1）燃焼域において NO の生成反応が進行する 時間を一定とみなす。

2）NO の解離反応の速度は非常に小さいものと して,これを無視する。

このようにして求められた空気予熱と $\mathrm{CO}_{2}$ 混入の 場合の見かけの活性化エネルギーは約 $37000 \mathrm{kcal} /$ $\mathrm{kmol}$ であり, 図中破線で示した重油燃焼の排ガス循 環の場合とほぼ同じ数值となった。ただし， $\mathrm{N}_{2}$ と $\mathrm{A}$ 混入の場合の活性化エネルギ一はこの值より小さい值 をもつ。この原因については現在研究中である。

(1)，(2)式の Zeldovich 機構による NO 生成速度で は, 通常, 次の $\mathrm{O}$ 原子の平衡

$$
\frac{1}{2} \mathrm{O}_{2}+\mathrm{M}=\mathrm{O}+\mathrm{M}
$$

と，Nについての定常状態を仮定して以下のような值 が示されている1)。

$$
\begin{gathered}
\frac{d[\mathrm{NO}]}{d \tau}=k_{\text {zeld. }}\left[\mathrm{N}_{2}\right]\left[\mathrm{O}_{2}\right]^{\frac{1}{2}} \mathrm{ppm} / \mathrm{s} \\
k_{\text {zeld. }}=2.0 \times 10^{9} \exp (-129000 / R T) \\
1 /(\mathrm{ppm})^{\frac{1}{2}} \cdot \mathrm{s}
\end{gathered}
$$

このように Zeldovich 機構の $\mathrm{N}_{2}, \mathrm{O}_{2}$ の 2 分子反 
応表示による活性化エネルギーは $129000 \mathrm{kcal} / \mathrm{kmol}$ あり,ここで得られた值よりかなり大きく, 反応速度 定数の温度に対する依存性が強い。つまり, 今回の反 応速度定数を用いると，かなり燃焼ガス温度が低い場 合にも, 相当量の $\mathrm{NO}_{x}$ の生成が算出されることにな る。式(9)は火炎後流の燃焼ガスに対して求められたも のであり, 火炎内においては, 前述したような Prompt NO などの現象があって, ここで得られたょうな, Zeldovich 機構より温度に対する依存性の少ない反応 速度を示すことは十分考えられることである。特に拡 散然焼においては火炎の領域が長く，その影響も強く 表われるものと考えられる。

次にここで得られた生成速度を用いて $\mathrm{NO}_{x}$ の生成 過程の推算を行ない，実測濃度との対応を考えてみ る。

\section{$4 \cdot 2 \mathrm{NO}_{x}$ 生成過程の推算}

ここでは，燃料に空気を予混合したときのデータを 推算例としてとり上げる。Fig. 6 は $Q_{a d d} / Q_{f}$ に対す る $\mathrm{NO}_{x}$ 濃度を示したものであり, Fig. 7 はいくつか の $Q_{a d d} / Q_{f}$ についての燃焼ガスの温度分布を表示し たものである。Fig. 6 では, 後述の実測濃度の対応か ら計測時の濃度のままで表示している。同図の換算濃 度表示はすでに第 1 報に示してある。

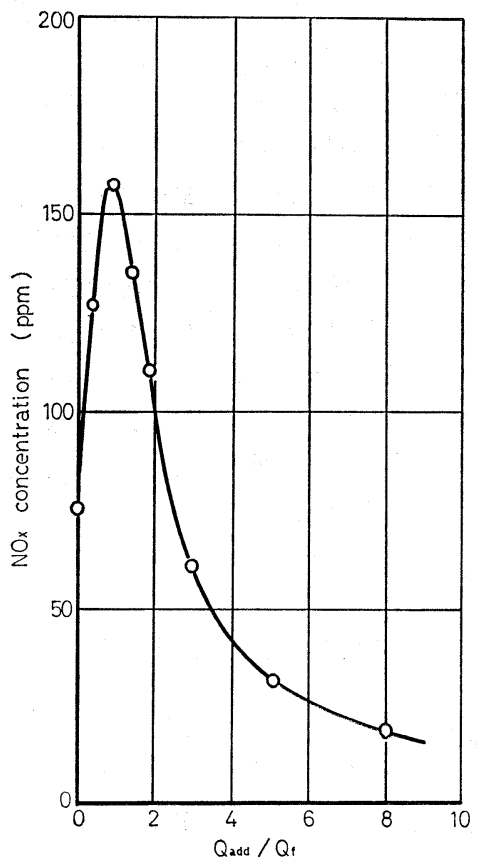

Fig. 6 Relation between $\mathrm{NO}_{x}$ emission and $\boldsymbol{Q}_{a d d} / \boldsymbol{Q}_{f}$

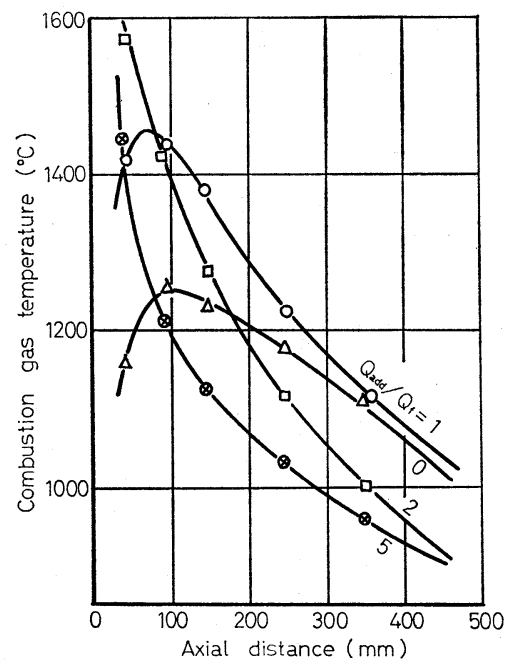

Fig. 7 Combustion gas temperature profiles for varying $\boldsymbol{Q}_{a d d} / \boldsymbol{Q}_{f}$

Fig. 7 の温度は, 各測定孔断面で計測した燃焼ガス 温度の最高值を示しているが, 半径方向の温度分布に はあまり大きな差はなく, 実用上代表值として使用で きる。

前述の反応速度定数においては, まだ頻度係数が求 められていないが，これは以下に述べるよらな $\mathrm{NO}_{x}$ 推算法をいろいろな場合に適用しながら, 実測 $\mathrm{NO}_{x}$ 量と合うように決定した。結局, 反応速度定数として 次のような值が得られる。

$$
k=2.2 \times 10^{-3} \exp (-37000 / R T)
$$$$
1 / \mathrm{ppm} \cdot \mathrm{s}
$$

生成速度は

$$
\frac{d[\mathrm{NO}]}{d \tau}=k\left[\mathrm{~N}_{2}\right]\left[\mathrm{O}_{2}\right] \quad \mathrm{ppm} / \mathrm{s}
$$

で表わされるから，(10)式の反応速度定数を代入して， 温度履歴にそって積分していけば，NOの生成量が求 められる。

$$
[\mathrm{NO}]=\int k\left[\mathrm{~N}_{2}\right]\left[\mathrm{O}_{2}\right] d \tau \quad \mathrm{ppm}
$$

ここでは次のようにして数值積分を行なった。

すなわち, Fig. 8 亿示すように温度分布を間隔 $l$ で 有限個に分割し， 1 区間における燃焼ガスの滞留時間 $\tau_{n}$ を，その区間の平均温度 $T_{n}$ を用いて(13)式のよう に求める。この場合, 半径方向の燃焼ガス流速の一様 性を仮定している。通常, $l$ は $10 \mathrm{~mm}$ として計算し た。

$$
\tau_{n}=\frac{l}{v} \cdot \frac{273}{T_{n}} \quad \mathrm{~s}
$$




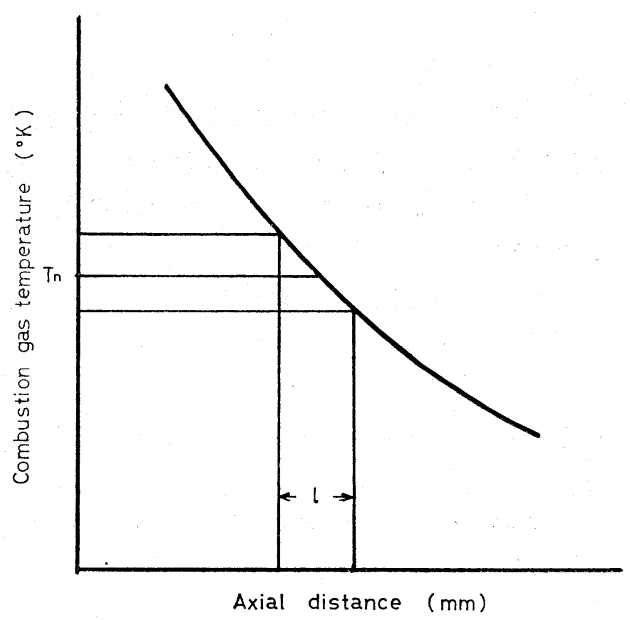

Fig. 8 Definition of reaction temperature in one division

$l$; 分割間隔 $\mathrm{m} \mathrm{m}$

$v$; 標準状態での燃焼ガスの流速 $\mathrm{mm} / \mathrm{s}$

$T, 1$ 区間における平均燃焼ガス温度 ${ }^{\circ} \mathrm{K}$

滞留時間が求まると, 次式に従い, 反応温度を $T_{n}$ として一区間における $\mathrm{NO}_{x}$ 生成量 $\left[\mathrm{NO}_{x}\right]_{\mathrm{th}, n}$ が計 算できる。

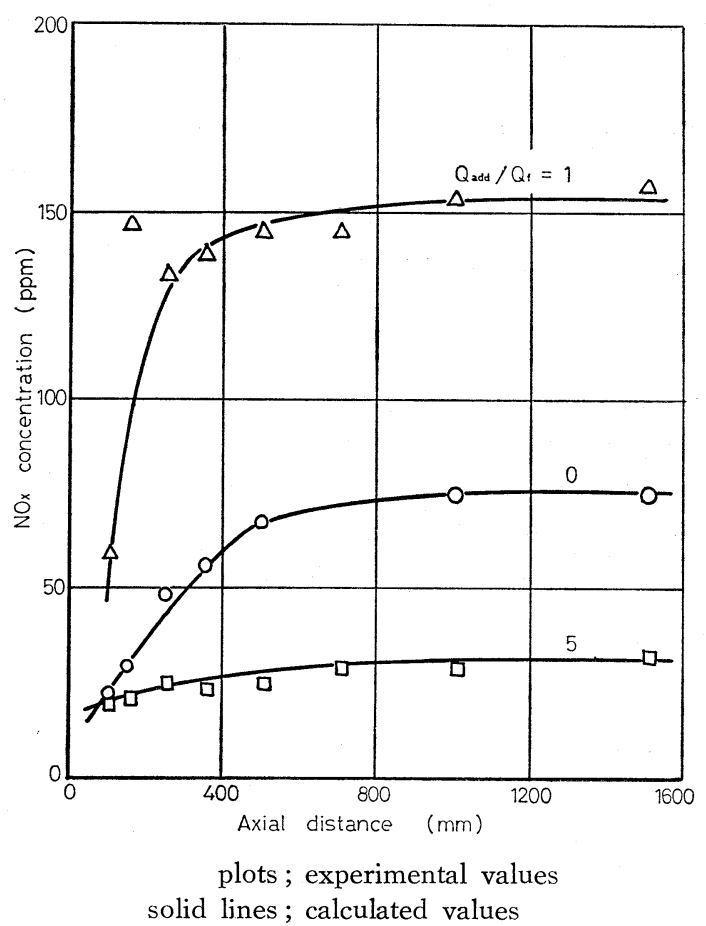

Fig. $9 \mathrm{NO}_{x}$ concentration profiles

$$
\left[\mathrm{NO}_{x}\right]_{\text {th, } n}=\left[\mathrm{N}_{2}\right]\left[\mathrm{O}_{2}\right] k_{n} \tau_{n} \quad \mathrm{ppm}
$$

$\left[\mathrm{N}_{2}\right],\left[\mathrm{O}_{2}\right]$; 燃焼ガスの平衡濃度 $\mathrm{ppm}$ $\mathrm{NO}_{x}$ 排出量 $\left[\mathrm{NO}_{x}\right]_{\mathrm{th}, t}$ は全区間の生成量を合計し たものであり,バーナーからある距離における濃度 は，そこまでの区間の生成量をたし合せて求めること ができる。

$\left[\mathrm{NO}_{x}\right]_{\mathrm{th}, t}=\sum\left[\mathrm{N}_{2}\right]\left[\mathrm{O}_{2}\right] k_{n} \tau_{n} \quad \mathrm{ppm}$

Fig. 9 には, このようにして求めた $\mathrm{NO}_{x}$ の生成過 程を実線で，また実測濃度をプロットで示している。 実測值と推算值は, 最終濃度はもちろん, 途中の生成 過程も非常によく一致していることがわかる。

以上のようにして，拡散燃燒における $\mathrm{NO}_{x}$ 生成量 の推定を行なうことができる。

\section{5. 結 論}

第 1 報と同じ装置を用いて，二段燃燒や，燃焼用空 気中に $\mathrm{N}_{2}, \mathrm{CO}_{2}, \mathrm{~A}$ を混入することによって排ガス 循環のモデル化実験を行ない，これら抑制対策の効果 について考察した。さらに，2,3 の実験結果を用いて 実用的な, 拡散燃焼における $\mathrm{NO}_{x}$ の生成速度を示し, それを用いて燃焼ガスの温度履歴から $\mathrm{NO}_{x}$ の生成量 を推定し，実測濃度との比較をこころみた。結論とし ては，次のような事項があげられる。

1) Thermal $\mathrm{NO}_{x}$ 抑制対策としての排ガス循環は, かなり効果的なことが推測される。燃焼用空気へ の添加物としては $\mathrm{CO}_{2}$ の効果が大きい。これは, $\mathrm{CO}_{2}$ の熱容量が大きく，燃焼温度の低下の割合 が高いためである。 $\mathrm{N}_{2}$ も A よりかなり燃焼温度 は低下するが，燃焼域における $\mathrm{N}_{2}$ の分圧も高く なるので， A 混入の場合と同程度の排出量を示 す。

2) 二段燃焼を行なら場合には，一段目での燃料之 空気の混合特性が良好なほど，その効果が大き い。混合が悪い場合には，一段目空気比が高いと きに抑制効果を示さないことがある。

3）拡散燃焼における，実用的な $\mathrm{NO}_{x}$ 生成速度に ついて，見かけ上の生成反応として次の反応を考 え,

$$
\mathrm{N}_{2}+\mathrm{O}_{2} \stackrel{k}{\longrightarrow} 2 \mathrm{NO}
$$

反応速度定数として次式を得た。

$$
k=2.2 \times 10^{-3} \exp .(-37000 / R T) 1 / \mathrm{ppm} \cdot \mathrm{s}
$$

4) 上記の反応速度と燃焼ガスの温度履歴から推算 した $\mathrm{NO}_{x}$ 生成過程は実測濃度の傾向と非常によ く一致した。

ここで示した反応速度定数をそのまま用いて実装置 
における $\mathrm{NO}_{x}$ 生成量の推定を行ならのは，まだ問題 点が多い。特に頻度俰数の值は, 本実験の結果に合せ る形で決定したものであり，これがすべての場合に適 用できるとは考え難い。ここで述べた推算法は，ある 条件に扔いて $\mathrm{NO}_{x}$ 濃度と温度履歴を調べて, その対 応から頻度係数を決定し, 他の温度夏歷のときの $\mathrm{NO}_{x}$ 排出量を推定するといら形で使用してもらいたい。

また, 実装置では燃焼室内での流れが非常に複雑で あり,ここで仮定できたような温度分布の一次元性を 保証できないことがほとんどである。この場合には燃 燒室内のフローパターン，温度分布を詳細に調ベ，流 線にそってここで示したような計算をとっていけばよ いことが推論できるが，はなはだ繁雑になる久点があ
り, 実装置における $\mathrm{NO}_{x}$ 量の正確な推定は非常に難 しいといわざるを得ない。

終りに, 本研究に際し, 終始ご指導頂いた小泉睦男 早大教授に深く感謝するとともに, 実験の遂行に協力 頂いた当時早大学生, 佐々木恒己, 清水敬二の両君に 謝意を表します。

\section{文献}

1) Ya.B. Zeldovich, Acta physicochim., URSS, 21, 577 (1946)

2) C.P. Fenimore, 13 th Symp. on Combustion, 373 (1971)

3) C.T. Bowman, Combustion Sci. and Tech, 3, 37 (1971)

\section{NOx Formation in Diffusion Flame (II) \\ - Properties of Some NOx Control Techniques and Prediction Method of NOx Formation}

by Katsuya Nagata \& Masahiko Mochizuki

(Waseda University)

SYNOPSIS : -In part (II), using the same apparatus in part (I) the effect of some $\mathrm{NO}_{x}$ reduction techniques is studied.

Practical $\mathrm{NO}_{x}$ formation rate obtained through experimental results in this paper and $\mathrm{NO}_{x}$ formation process is calculated by applying this rate to temperature profiles of combustion gas.

The results are as follow.

1) $\mathrm{CO}_{2}$ pre-mixing in the combustion air indicates higher $\mathrm{NO}_{x}$ reduction than $\mathrm{N}_{2}$ or A. $\mathrm{N}_{2}$ pre-mixing is same to $\mathrm{A}$, in spite of lower combustion temperature. Because $\mathrm{N}_{2}$ concentration is higher than $A$.

2) Effect of two-stage combustion is greater as mixing more improves.

3) The calculated concentration using the $\mathrm{NO}_{x}$ formation rate and temperature history diagram coincides with experimental data. 